\title{
pUDK-HGF Gene Therapy to Relieve CLI Rest Pain and Ulcers: A Phase II, Double-Blind, Randomized Placebo- Controlled Trial
}

\section{Yongquan Gu}

Beijing Xuanwu Hospital

\section{Shijun Cui}

Xuanwu Hospital

Changjian Liu

Nanjing Drum Hospital

Jichun Zhao

West China Hospital

\section{Ming Li}

Zhejiang University

\section{Yiqing Li}

Wuhan Union Hospital

\section{Xinglong Yang}

Nanchang University

\section{Bonan Lv}

Hebei General Hospital

\section{Mingzhang Li}

Baotou General Hospital

\section{Wenguang Zhao}

Jilin University

\section{Wei Guo}

Chinese PLA General Hospital

\section{Jianhua Huang}

Xiangya Hospital Central South University

\section{Wen Huang}

Chongqing University

\section{Zhenming Qiu}

Taizhou Hospital of Zhejiang Province

\section{Jun Zhao}

: Shanghai Sixth Peoples Hospital

\section{Ping Yin}

Huazhong University of Science and Technology

\section{Tingting Qiu}

Huazhong University of Science and Technology

\section{Dan zhu}

Humanwell Healthcare Co. 


\section{Wenjie Sun}

Humanwell Healthcare Co.

\section{Yuxin Lu}

Beijing Institute of Radiation Medicine

\section{Xiaochen Cheng}

Beijing Institute of Radiation Medicine

\section{Li Du}

Beijing Institute of Radiation Medicine

\section{Qinglin Zhang ( $\sim$ qinglz2003@126.com )}

Beijing Institute of Radiational Medicine

\section{Zuze Wu}

Beijing Institute of Radiation Medicine

\section{Original investigation}

Keywords: Peripheral arterial disease, Critical limb ischemia, Gene therapy, Pain at rest, Ulceration, Hepatocyte growth factor, pUDK-HGF treatment, Phase II clinical trial

Posted Date: November 5th, 2020

DOI: https://doi.org/10.21203/rs.3.rs-101447/v1

License: (c) (i) This work is licensed under a Creative Commons Attribution 4.0 International License. Read Full License

Version of Record: A version of this preprint was published at Human Gene Therapy on May 21st, 2021. See the published version at https://doi.org/10.1089/hum.2020.290. 


\section{Abstract}

Background

Critical limb ischemia (CLI) has become a global problem. Less invasive therapy is needed. Hepatocyte growth factor (HGF) is one of the most potent angiogenic protein and the plasmid encoding human hepatocyte growth factor (HGF) is considered to be the most promising gene therapy for CLI.

Methods

We conducted a randomised, double-blind, placebo-controlled trial to assess the efficacy and safety of intramuscular injection of plasmid pUDK-HGF expressing HGF. Pain-at-rest patients and ulcer patients were enrolled as two cohorts and randomized to receive intramuscular injection of placebo or pUDK-HGF. Efficacy assessments included pain scale, ulcer size, $\mathrm{TBI}, \mathrm{ABI}$, and $\mathrm{TCPO}_{2}$ over 180 day. Safety analysis was based on the occurrence of adverse events.

Results

In the pain-at-rest cohort, the proportion of patients with complete pain relief after receiving pUDK-HGF injections was significantly higher than that of the placebo group on day $180(p=0.0148)$. More responders with $>50 \%$ pain reduction were also observed in the pUDK-HGF groups than in the placebo groups $(p=0.0168)$. In the ulcer cohort of patients, pUDK-HGF treatment tended to be superior to the placebo in the percentage of patients with both complete ulcer healing and $>50 \%$ ulcer healing. No significant differences in the incidence of adverse events or serious adverse events were observed among the groups.

\section{Conclusion}

Intramuscular injection of pUDK-HGF is safe and can significantly reduce pain-at-rest and possibly promotes ulcer healing in CLI patients. The mid dose pUDK-HGF $(6 \mathrm{mg})$ was the most efficacious, and is an appropriate dose for phase III clinical trial.

Clinical Trial Registration

China Food and Drug Administration number: 2013L00637, Data: 2013/03/15. China Clinical Trial Registry URL: http://www. chinadrugtrials.org.cn. Unique Identifier: 20130378)

\section{Background}

Peripheral arterial disease (PAD), a local manifestation of atherosclerosis, has become a global problem. A recent survey reported that $6.6 \%$ (estimated 45.3 million) of the adult ( $>35$ years of age) Chinese population have PAD, the prevalence of which increases significantly in those aged $\geq 75$ years (11.8 \%).[1] Older age, Han ethnicity, smoking, education level, hypertension, coronary artery disease, diabetes, dyslipidemia, and rural residences are associated with a higher risk for PAD. China still faces a prevention and management challenge for PAD. Critical limb ischemia (CLI), the most severe limb manifestation of PAD, is associated with chronic ischemic pain at rest and/or the presence of ischemic skin lesions. Although open bypass surgery and endovascular revascularization are currently considered the first treatment choices for CLI, approximately $50 \%$ of patients with CLI are poor candidates for these standard therapies [2]. Therefore, less invasive therapy is needed for improving limb perfusion in these patients and angiogenesis offers hope for patients who cannot undergo standard revascularization treatment. Hepatocyte growth factor (HGF) is one of the most potent angiogenic proteins. Indeed, human HGF gene-encoding plasmids are currently considered to be the most promising type of gene therapy for CLI, and several clinical trials using this type of CLI therapy have been 
performed in the USA, Japan and China [3-12] However, some results from these clinical trials are controversial, and a large sample-sized clinical study is needed to verify the potential beneficial efficacy of HGF plasmid therapy for CLI.

pUDK-HGF is a naked plasmid DNA encoding the human HGF gene [13]. Based on our rat and dog ischemic hindlimb models, our pre-clinical studies have indicated that pUDK-HGF has therapeutic potential in both cases [13-17]. Intramuscular injection of pUDK-HGF into the rat hindlimb resulted in strong HGF expression and significantly increased capillary density in the ischemic tissue. It also significantly increased the blood flow in collateral vessels in either completely or partly femoral artery ligation hindlimb dog model. Furthermore, no obvious toxic effects were observed in the rat and dog toxicology studies. In fact, the results of a phase I clinical study [3] showed that intramuscular injection of pUDK-HGF is safe, and no serious adverse events (SAEs) were observed over the 3-month follow-up. Notably, pUDKHGF therapy significantly decreased the pain severity and improved ulcer healing the CLI patients. The mean visual analogue scale (VAS) for all the patients decreased significantly from a baseline 4.52 to 0.30 (P凶0.01 versus baseline) on day 90 posttreatment with pUDK-HGF. Fourteen patients reported complete pain relief and a $100 \%$ VAS score reduction on day 90. Of the four patients with ulcers, two ulcers showed complete closure, while the other two patients showed ulcer size reductions $>25 \%$ in the long axis diameter after pUDK-HGF treatment. Of the five patients with gangrene, one gangrenous wound was completely closured on day 90 and two gangrenous wounds showed marked size reductions. These results provided the rationale for conducting a larger-sized clinical study to evaluate the safety and efficacy of pUDK-HGF for CLI gene therapy.

In this phase II study, we performed a multicenter, randomized, double-blinded, placebo-controlled trial of pUDK-HGF injection in two cohorts of patients with CLI, including 119 pain-at-rest patients and 121 patients with ulcers, to evaluate the safety and efficacy of pUDK-HGF in these patients, and to determine an appropriate dose for a phase III clinical trial.

\section{Methods}

\section{Plasmid pUDK-HGF}

The human HGF gene-encoding recombinant pUDK-HGF plasmid, which is driven by the human cytomegalovirus promoter (EcoRI/Notl, $2.2 \mathrm{kbp}$ ), was inserted into the pUDK vector [13]. pUDK-HGF was provided by Humanwell Healthcare (Group) Co. Ltd, Wuhan, China. The product was supplied in a sterile glass vial at a concentration of 2 $\mathrm{mg} / \mathrm{mL}$ in the formulation solution, and stored at $4-8^{\circ} \mathrm{C}$. pUDK-HGF solution and saline are visually indistinguishable.

\section{Patient Population}

\section{Inclusion Criteria}

Patients aged 20-80 years with ischemic lower limb arterial disease (Rutherford Categories 4-6), which included those with arteriosclerosis obliterans, diabetic arteriosclerosis obliterans, and thromboangiitis obliterans, were enrolled. Patients were required to have significant stenosis ( $\$ 75 \%$ ) of one or more of superficial femoral and popliteal arteries as verified by digital subtraction angiography, computerized tomography angiography or magnetic resonance angiography within 12 months. Patients were also required to have VAS scores of $₫ 3$. The pain-at-rest patients were required to have baseline ankle pressures below $40 \mathrm{mmHg}$ or toe pressures below $<30 \mathrm{mmHg}$. Patients with ischemic ulcers or local gangrene were required to have baseline ankle pressures below $60 \mathrm{mmHg}$ or toe pressures below 40 $\mathrm{mmHg}$. Patients were also required to have normal laboratory examinations for tumors, including chest $\mathrm{X}$-ray, tumor marker detection (including alpha-fetoprotein), chorioembryonic antigen, prostate-specific antigen, carbohydrate antigen 19-9, cancer antigen 125), Pap smear, breast X-ray mammography, and fecal occult blood. The female patients must have undergone sterilization or have experienced amenorrhea for more than 1 year, and the pregnancy tests must be negative. 


\section{Exclusion criteria}

The major exclusion criteria included patients with a vascular disease prognosis who would require amputation within 3 months of the study's initiation. It also included patients who had undergone a successful revascularization procedure within the previous 12 weeks, or experienced vascular reconstruction failure 4 weeks prior to the study's initiation. Patients with stage 3 or higher retinopathy, malignant tumors or had suspected malignant tumors (by screening tests), or had resistant hypertension (systolic blood pressure $>200 \mathrm{mmHg}$ or diastolic blood pressure $>115$ $\mathrm{mmHg}$ ), or had any type infection (e.g., hepatitis B and/or C, AIDS or syphilis) were also excluded, as were patients with the following laboratory results: hemoglobin $<80 \mathrm{~g} / \mathrm{L}$, white blood cell count $<3.0 \times 109$ / L, platelets $<75 \times 109 / \mathrm{L}$, aspartate transaminase or alanine transaminase $>2 \times$ upper limits of normal (ULN), creatine or blood urea nitrogen (Bun) $>1.2 \times$ ULN, and hemoglobin A1c > $11.0 \%$.

\section{Withdrawal Criteria}

Cilostazol tablets were provided as a basic therapeutic drug in this trial, and the patients were withdrawn from using any other antiplatelet or vasodilation agent. For ethical consideration, patients could choose acetaminol tablets (Tylenol), tramadol (sustained release tablets) or controlled release morphine tablets according to the degree of pain. Patients were also withdrawn from the study for poor compliance, unwillingness to continue, for other severe concomitant diseases, or after missing a visit.

\section{Study Design \\ Randomization}

This double-blind, randomized, placebo-controlled, 14-center trial was designed to assess the safety and efficacy of intramuscular injection of pUDK-HGF in CLI patients. Two cohorts of patients were enrolled, and 119 patients with pain at rest were evaluated for pain relief, whereas 121 patients with ulcers were evaluated for ulcer healing. The patients in each cohort were randomized 1:1:1:1 to receive intramuscular injection of placebo $(0.9 \%$ saline), or 1 of 3 doses of pUDK-HGF (low-dose, 4.0; middle-dose, 6.0; high-dose, $8.0 \mathrm{mg}$ ) on days 0, 14, and 28.

\section{Intramuscular Injection of Plasmid pUDK-HGF}

The patients received 32-site injections in the calf and/or thigh muscles of the affected limb on days 0,14 , and 28 . The high-dose pUDK-HGF (8 mg) group of patients received 32- site injections of $0.25 \mathrm{mg} / 0.5 \mathrm{ml}$ pUDK-HGF, the mid-dose pUDK-HGF (6 mg dose) group of patients received 24 injections of $0.25 \mathrm{mg} / 0.5 \mathrm{ml}$ pUDK-HGF, or $80.5 \mathrm{ml}$ injections of the placebo. The low-dose pUDK-HGF $(4 \mathrm{mg})$ group of patients received 16 injections of $0.25 \mathrm{mg} / 0.5 \mathrm{ml}$ pUDK-HGF, or 16 injections of $0.5 \mathrm{ml}$ of the placebo. Patients in the placebo group received 32 injections of $0.5 \mathrm{ml}$ of $0.9 \%$ saline. The first injection site was chosen to be $2 \mathrm{~cm}$ above the starting point of the stenosis based on the vascular disease anatomy, whereas the others were regularly distributed following the blood vessel direction at $2 \mathrm{~cm}$ apart.

\section{Efficacy Assessments}

Efficacy assessments included pain scale, ulcer size, $\mathrm{TBI}, \mathrm{ABI}$, and $\mathrm{TcPO}_{2}$. They were evaluated on screening, and on days $0,14,28,60,90$, and 180 after treatment. Pain intensity was measured using the VAS score on screening and on days 0 (preinjection), 14 and 28, and on days 30,60,90, and 180. The ulcer size was measured using Anshutuo sticking strips at baseline and at every visit throughout the 6-month follow-up period.

The $\mathrm{TcPO}_{2}$ values for the chest, thigh, calf and foot were measured. The minimum ratio of limb to chest $\mathrm{TcPO}_{2}$ on each visit was used to evaluate changes in transcutaneous oxygen tension. 
The primary treatment endpoint was the proportion of patients with complete relief of resting pain (for rest pain patients) or with complete ulcer closure (for ulcer patients) on day 180 . The secondary outcome included the percentage of patients with $>50 \%$ reduction in the pain VAS score or a $>50 \%$ reduction in ulcer size, as well as a change in $\mathrm{TCPO}_{2}, \mathrm{ABI}$, and $\mathrm{TBI}$, amputation rate, and mortality from baseline to the 6-month follow-up.

\section{Safety Assessments}

Safety analysis was based on the occurrence of adverse events according to the NCI Common Terminology Criteria for Adverse Events v3.0, and included physical examination, concomitant medication, laboratory examinations such as electrocardiogram, blood chemistry, hematology, coagulation, urinalysis, retinopathy screening, and tumor screening.

The protocol was approved by the Research Ethics Boards for all sites and all the patients provided written informed consent before participating in this study. The trial was carefully monitored by the members of an independent data monitoring committee who reviewed the accruing and unblinded data.

\section{Statistical Analysis}

Statistical analysis was performed using SAS, version 9.2, with $p<0.05$ considered to be statistically significant. A full analysis set and a per-protocol set were performed to evaluate the comprehensive efficacy. Safety analysis was evaluated using the safety analysis set. All continuous data ( $\mathrm{BBI}, \mathrm{VAS}$ ) were expressed as the median \pm standard deviation and interquartile ranges. Comparisons between the baseline data and post treatment data were performed by a $\chi 2$ test. Categorical variables were expressed using frequency or percentage $(n, \%)$ and analyzed by Fisher's exact test.

\section{Results}

\section{Baseline Demographics and Medical Histories}

Between May 10, 2013, and August 16, 2014, the 288 patients who consented to participate in this study were screened in accordance with the inclusion and exclusion criteria. Pain-at-rest patients and ulcer patients were enrolled as two cohorts, with each cohort randomized 1:1:1:1 to receive intramuscular injection of placebo or 1 of 3 doses of pUDK-HGF $(4.0,6.0$, or $8.0 \mathrm{mg})$ on days 0,14 , and 28 , as shown in Figure 1.

The pain-at-rest cohort comprised 119 enrolled patients who were randomized into the following three pUDK-HGF treatment groups: high-dose $(n=28)$, mid-range dose $(n=30)$, low-dose $(n=27)$, and placebo $(n=34)$. Five patients who experienced SAEs or were lost to follow up did not complete the study, and 14 patients were withdrawn for using non-permitted antiplatelet agents, or for violating the enrollment criteria. Finally, 100 patients (high dose, $n=22$; midrange dose, $n=25$; low dose, $n=24$; placebo, $n=29$ ) completed the study and were available for the efficacy analysis. The baseline characteristics of the four groups were homogeneous and comparable with no significant differences in age, sex, demographic origin, or pain characteristics (Table 1).

The cohort of ulcer patients ( $n=121)$ were randomized into the following four groups: pUDK-HGF high dose $(n=30)$, mid dose $(n=30)$, low dose $(n=31)$, or placebo $(n=30)$. Nineteen patients that were lost to follow up, underwent bypass, or died, did not complete the study. Thirteen patients who violated the inclusion criteria were withdraw. Eighty-nine patients (high dose, $n=22$; mid-range dose, $n=25$; low dose, $n=19$; placebo, $n=23$ ) completed the study and were available for the efficacy analysis. The baseline characteristics of the patients are summarized in Table 2.

\section{Efficacy Endpoints in the Pain-at-Rest Patient Cohort}


Rest pain was evaluated at each in-clinic visit (screening, and on days $0,14,28,60,90,180$ ) using VAS. The primary end point was the proportion of patients with complete pain relief and $100 \%$ reduction in their VAS scores on day 180. As shown in Figure 2, a significantly higher proportion of patients in the pUDK-HGF groups $(62.50 \%, 72.00 \%$, or $63.64 \%$ in the high-dose, mid-dose, or low-dose group, respectively) experienced complete pain relief and achieved the primary end point on day 180 when compared with patients in the placebo group $(31.03 \%, p=0.0148)$.

The secondary efficacy measures included the VAS change from baseline and the number of responding patients. The VAS score was lowered in all of the pUDK-HGF patients and these recipients showed statistically significant differences when compared with the placebo group on days 60, 90 and 180 (Table 3 and Figure 3). A much greater reduction was observed in the group who received the mid- dose pUDK-HGF (compared with the other groups), with a 5.42-point reduction seen in the baseline Vas score on day $180(95 \% \mathrm{Cl},-5.98,-4.86, \mathrm{p}=0.0041)$.

Patients experiencing a $>50 \%$ VAS reduction from baseline were defined as responding patients. As shown in Figure 2 , the number of responding patients across all the pUDK-HGF groups was significantly higher than the number in the placebo group (65.52\% for the placebo versus $86.36 \%, 100.00 \%$, or $95.83 \%$ for the high-dose, mid-dose, or low-dose groups, respectively; $p=0.0168)$.

Of the 100 patients, six used analgesics during the trial (four in the placebo group, 1 in the high-dose group, and one in the low-dose group), and the VAS changes in the 94 remaining patients not taking analgesics showed a similar trend to that seen in all the available patients (Supplementary data).

There were no statistically significant differences in the transcutaneous oxygen pressure $\left(\mathrm{TcPO}_{2}\right)$ ratio among the four groups throughout the study period, but the $\mathrm{TcPO}_{2}$ ratio in each group significantly increased from baseline onwards (as shown in Figure 4). There was no difference in the ankle brachial index (ABI) or the toe brachial index (TBI) among the groups at any of the time points. Only one patient in the high-dose pUDK-HGF group had an amputation in the left thigh during the trial.

\section{Efficacy Endpoints in Ulcer Patients}

In the cohort of ulcer patients, pUDK-HGF treatment tended to be superior to the placebo in reduction the ulcer area with ulcers $<1000 \mathrm{~mm}^{2}$ at baseline as shown in Table 4 and Figure 5.

The primary end point was the percentage of patients with complete ulcer closure on day 180 . The more patients with ulcers smaller than $1000 \mathrm{~mm}^{2}$ at baseline in all the pUDK-HGF groups reached this primary end point compared with the placebo group (44.4\% in the placebo group versus $55.6 \%, 75.0 \%$, and $61.1 \%$ in the high-dose, mid-dose, or low-dose groups, $p>0.05$ ) on day 180 , but these differences were not statistically significant. Only one ulcer (10 ulcers in total) larger than $1000 \mathrm{~mm}^{2}$ on baseline had completely healed on day 180 in the high-dose pUDK-HGF treatment group.

The second end point was the percentage of patients displaying a $>50 \%$ reduction in their ulcer size from baseline (defined as responding patients). More responding patients were observed in the mid-dose pUDK-HGF treatment (83.3 $\%)$ than in the placebo group $(72.2 \%)$ on day 180.

The VAS score was also evaluated in all the ulcer patients as the second end point, and the mid-dose pUDK-HGF treatment produced the greatest reduction in the VAS pain score. Twelve patients $(12 / 25,48.0 \%)$ who received the middose pUDK-HGF treatment reported complete pain relief on day 180 , whereas only three reported this effect in the placebo group $(3 / 23,13.0 \%, p=0.0820)$. Altogether, 23 patients $(23 / 25,92.0 \%)$ in the group who received the mid-dose pUDK-HGF treatment reported a $>50 \%$ reduction in the VAS pain score compared with the placebo group $(14 / 23,60.87$ $\%, p=0.0010)$. 
Although the $\mathrm{ABI}, \mathrm{TBI}$ and $\mathrm{TcPO}_{2}$ measurements in all the pUDK-HGF treatment groups showed obvious increases from baseline to day 180 , no statistical differences were apparent for any of the time points during the follow up visits.

\section{Safety and Tolerability}

A safety assessment was also conducted on the 240 patients who received at least one injection of pUDK-HGF or placebo in the two cohorts. Intramuscular injections of pUDK-HGF were well tolerated, and no unexpected SAEs were observed during the 6-month study period. There were no statistically significant differences in the occurrence of adverse events (AEs), SAEs, adverse reactions or injection-site reactions among the three pUDK-HGF and placebo groups, as shown in Figure 6.

In total, 159 AEs (159/240, 66.25\%) occurred in all patients. These AEs, which included headache, dizziness, upper respiratory tract infection, hypertension, diarrhea, and abnormal laboratory indexes, were unrelated to the treatment and did not require any significant interventions during the study.

Twenty-one SAEs $(21 / 240,8.75 \%)$ occurred in patients over the course of the trial, with seven of them $(7 / 58,12.07 \%)$ occurring in the high-dose patients, none $(0 / 60,0 \%)$ occurring in the mid-dose patients, eight occurring $(8 / 58,13.79 \%)$ in the low-dose patients, and six $(6 / 64,9.38 \%)$ occurring in the placebo group. The SAEs were pulmonary infection, thromboembolic events, heart failure, double leg pain, acute cerebral embolism, foot infection and necrosis, gastric perforation, lower extremity arteriosclerosis progression, ulcer progression, and death; they were classified as being unrelated to pUDK-HGF or placebo treatments.

Three patients died of cerebral embolism (in the high-dose pUDK-HGF group), asthma (in the high-dose group) and CLI progression (in the low-dose group), and these events were considered to be independent of pUDK-HGF treatment. There was no progression of diabetic retinopathy, and no developing malignancy over the study period.

Altogether, five adverse reactions occurred over the course of the study, with two patients displaying limb edema (one in the placebo group and one in the low dose group), while one in the mid-dose group had pruritus, one in the mid-dose group had limb pain, and one in the mid-dose group had an increased platelet count. These reactions, which were considered to be possibly related to pUDK-HGF administration or the placebo treatment, were alleviated without medical treatment during the follow-up period. Eight patients (placebo, 2; low-dose, 3; mid-dose, 2; and high-dose, 1) experienced mild injection site reactions including pain, itching, swelling, and bruising. The reactions were not treated and were alleviated during the follow-up period.

\section{Discussion}

Chronic CLI reflects the presence of significant atherosclerotic disease of the lower-extremity vessels in patients. Painat-rest and ulcerative lesions are two clinical manifestations of this disease state and the extent to which the different clinical stages advance varies according to the degree of ischemia and the patient's response to medical therapy. The primary goals in treating CLI is to relieve ischemic pain, heal ischemic ulcers, prevent limb loss, improve the patient's functionality and quality of life, and prolong their survival. In this phase II clinical trial, patients with pain at rest and skin ulcers were enrolled as two separate cohorts to study the efficacy and safety of intramuscular injection with naked plasmid pUDK-HGF. Complete relief of resting pain and complete ulcer closure were ethically selected as the primary end points for this study, according to the guidelines for the clinical investigation of medicinal products for the treatment of peripheral arterial occlusive disease from the European Medicines Agency.

In the pain-at-rest cohort, significantly more patients in the pUDK-HGF groups achieved the primary end point on day 180. The numbers of responding patients with $>50 \%$ pain relief in the pUDK-HGF groups were also significantly higher 
than those in the placebo groups on day 180. After the first injection of pUDK-HGF on day 0 , the VAS score reduced and showed statistically significant differences on days 60, 90 and 180 among the placebo and pUDK-HGF groups. This indicates that the patients who underwent pUDK-HGF treatment experienced long-term pain relief, rather than the temporary relief provided by analgesics.

Our preclinical study indicated that angiogenesis is the mechanism underlying the analgesic action of pUDK-HGF, whereby the establishment of collateral circulation occurs $[13,14]$. Our recent work indicated that intramuscular injections of pUDK-HGF promote blood flow and proliferation of satellite cells, and inhibit inflammatory cell recruitment, collagen accumulation, and the expression of pronociceptive factors in a rat skin/muscle incision and retraction model $[18,19] \cdot$ Intrathecal injection of pUDK-HGF inhibited spinal glial cell activation and reduced the cytotoxicity associated with expression of interleukin (IL)-1 $\beta$, IL-6, tumor necrosis factor $a$ and inducible NO synthase, as well as decreasing nitric oxide production from activated glial cells. These factors might also play a part in the pain relief mechanism of pUDK-HGF.

In the cohort of ulcer patients, pUDK-HGF treatment tended to be superior to the placebo in the higher percentage of patients displaying complete ulcer healing. The most completely healed ulcer had a baseline area $<1000 \mathrm{~mm}^{2}$, the average ulcer area was $250.17-266.15 \mathrm{~mm}^{2}$. Only one ulcer larger than $1000 \mathrm{~mm}^{2}$ at baseline $\left(1829.06 \mathrm{~mm}^{2}\right) \mathrm{showed}$ complete healing on completion of the study in the high dose pUDK-HGF group. These results suggest that the present treatment process promotes ulcer healing with an area less than $300 \mathrm{~mm}^{2}$, and the frequency of pUDK-HGF treatment via local injections should be increased or combined with topical application of pUDK-HGF.

In this study, the minimum value of the $\mathrm{TcPO}_{2}$ ratio for the anterior calf/chest, posterior calf/chest and dorsal foot/chest was used to evaluate the microcirculation status of the limbs to obviate the effect of environmental factors such as temperature, humidity and atmospheric pressure, among others [20]. This ratio was considered more reliable and comparable than direct $\mathrm{TcPO}_{2}$ measurements. The $\mathrm{TcPO}_{2}$ ratio in the pUDK-HGF treatment group increased significantly on 180 days when compared with the baseline, in both the pain relief cohort and the ulcer cohort; however, there were no statistical differences at any of the follow-up time points.

Altogether, 240 patients representing the two cohorts were analyzed for treatment safety. Most AEs and SAEs were classified as being unrelated to the treatment received, and were most likely caused by CLI or comorbid conditions. All pUDK-HGF doses were well tolerated by the patients.

Another important goal of this trial was to determine the appropriate pUDK-HGF dose for a phase III trial. In three pUDKHGF treatment groups, the mid-dose pUDK-HGF $(6 \mathrm{mg})$ provided the most effective pain relief in the pain-at-rest cohort and most effective ulcer healing in the cohort of ulcer patients. Therefore, the mid-dose pUDK-HGF appears to be the most appropriate dose for a phase III clinical trial.

The limitation of this study is that by dividing the limited number of patients into three pUDK-HGF dose groups and placebo group, although 120 patients were enrolled in each cohort. This resulted in a small baseline imbalance in the patients' characteristics and a trend outcome like that seen with wound healing, $\mathrm{TcPO}_{2}$. In a phase III clinical trial, the sample size will need to be enlarged, and the mid-dose of pUDK-HGF alone will be administrated to provide a clear result.

\section{Conclusions}

Above all, this phase II clinical study has demonstrated that intramuscular injection of pUDK-HGF is safe, can significantly reduce pain-at-rest in CLI patients, and possibly promotes better ulcer healing in CLI patients than the 
placebo. The mid-dose pUDK-HGF is recommended as an appropriate dose for a larger size phase III clinical trial of CLI therapy. Phase III clinical trials were approved by the China Food and Drug Administration (CFDA) in September 2017.

\section{Declarations}

\section{Acknowledgments}

The authors wish to thank the study participants for their time, effort, and commitment.

\section{Author contributions}

Z. Wu provided advice and directed the study. Y. Gu, P. Yin, and Q. Zhang designed research studies, S. Cui , C. Liu, J. Zhao, M. Li, Y. Li, X. Yang, B. Lv, M. Li, W. Zhao, W. Guo, J. Huang, W. Huang, Z. Qiu, and J. Zhao conducted clinical trials. T. Qin analyzed the data. D. Zhu, and W. Sun acquired data. Y. Lu, X. Cheng and L. Du provided technical or material support. Q. Zhang wrote the manuscript. All authors revised the manuscript and gave final approval for publication.

FUNDING: This work was supported by National Science and Technology Major Project, China, No.2014ZX09101-045002.

\section{AVAILABILITY OF DATA AND MATERIALS}

The datasets used and/or analysed during the current study are available from the corresponding author on reasonable request.

\section{ETHICS APPROVAL AND CONSENT TO PARTICIPATE}

This study was approved by the China Food and Drug Administration. All subjects provided written informed consent before participating in the trial.

\section{CONSENT FOR PUBLICATION}

Not applicable.

\section{COMPETING INTERESTS}

The authors declare that they have no competing interests.

\section{AUTHOR DETAILS}

1Vascular Surgery Department, Xuan Wu Hospital, Capital Medical University, Beijing, China;

2Vascular Surgery Department, Nanjin Drum Tower Hospital, Nanjing, China ;

3Vascular Surgery Department, West China Hospital, Sichuan University, Chengdu, China;

4Vascular Surgery Department, The First Affiliated Hospital of Medical School of Zhejiang University, Hangzhou, China;

5Vascular Surgery Department, Wuhan Union Hospital, Wuhan, China;

6 General Surgery Department, The First Affiliated Hospital of Nanchang University, Nanchang, China; 
7 General Surgery Department, Hebei General Hospital, Shijiazhuang, China;

8 General Surgery Department, Baotou Central Hospital, Baotou, China ;

9Vascular Surgery Department, The First Bethune Hospital of Jilin University, Changchun, China

10 Vascular Surgery Department, Chinese PLA General Hospital, Beijing, China;

11 Vascular Surgery Department, Xiangya Hospital Central South University, Changsha, China

12 Vascular Surgery Department, The First Affiliated Hospital of Chongqin Medical University, Chongqing, China

13 General Surgery Department, Taizhou Hospital of Zhejiang Province, Linhai, China

14 General Surgery Department, Shanghai Sixth People's Hospital Affiliated to Shanghai JiaoTong University, Shanghai, China

15 School of Public Health, Tongji Medical College, Huazhong University of Science and Technology, Wuhan, China 16 Humanwell Healthcare(Group) Co. Ltd, Wuhan, China.

17 Department of Experimental Hematology and Biochemistry, Beijing Institute of Radiation Medicine, Beijing, China

\section{References}

1. Wang Z, Wang X, Hao G, Chen Z, Zhang L, Shao L, Tian Y, Dong Y, Zheng C,Kang Y, Gao R. A national study of the prevalence and risk factors associated with peripheral arterial disease from China: The China Hypertension Survey, 2012-2015. International Journal of Cardiology. 2019; 275, 165-170.

2. Adam DJ, Beard JD, Cleveland T, Bell J, Bradbury AW, Forbes JF. BASIL trial participants. Bypass versus angioplasty in severe ischemia of the leg (BASIL): multicentre, randomized controlled trial. Lancet. 2005;366,1925-34.

3. Cui S, Guo L, Li X, Gu Y, Fu J, Dong L, Song H, Chen X, Lu Y, Hu C, Xiao F, Zhu D, Wu Z, Zhang Q. Clinical Safety and Preliminary Efficacy of Plasmid pUDK-HGF Expressing Human Hepatocyte Growth Factor (HGF) in Patients with Critical Limb Ischemia. Eur J Vasc Endovasc Surg (2015) 50,494-501.

4. Shigematsu H, Yasuda K, Iwai T, Sasajima T, Ishimaru S, Ohashi Y, Yamaguchi T, Ogihara T, Morishita R, Randomized, double-blind, placebo controlled clinical trial of hepatocyte growth factor plasmid for critical limb ischemia. Gene Ther 2010; 17:1152-1161.

5. Powell RJ, Goodney P, Mendelsohn FO, Moen EK, Annex BH, HGF-0205 Trial Investigators. Safety and efficacy of patient specific intramuscular injection of HGF plasmid gene therapy on limb perfusion and wound healing in patients with ischemic lower extremity ulceration: results of the HGF-0205 trial. J Vasc Surg 2010; 52: 1525-1530.

6. Morishita R, Makino H, Aoki M, Hashiya N, Yamasaki K, Azuma J, Taniyama Y, Sawa Y, Kaneda Y, Ogihara T, Phase I/Ila clinical trial of therapeutic angiogenesis using hepatocyte growth factor gene transfer to treat critical limb ischemia. Arterioscler Thromb Vasc Biol 2011; 31: 713-720.

7. Shigematsu H, Yasuda K, Sasajima T, Takano T, Miyata T, Ohta T, Tanemoto K, Obitsu Y, Iwai T, Ozaki S, Ogihara T, Morishita R; Transfection of human HGF plasmid DNA improves limb salvage in Buerger's disease patients with critical limb ischemia. Int Angiol 2011; 30: 140-149.

Page $11 / 28$ 
8. Powell RJ, Simons M, Mendelsohn FO, Daniel G, Henry TD, Koga M, Morishita R, Annex BH, Result of a double-blind, placebo-controlled study to assess the safety of intramuscular injection of hepatocyte growth factor plasmid to improve limb perfusion in patients with critical limb ischemia. Circulation. 2008;118:58-65.

9. Makino H, Aoki M, Hashiya N, Yamasaki K, Azuma J, Sawa Y, Kaneda Y, Ogihara T, Morishita R, Long-term follow-up evaluation of results from clinical trial using hepatocyte growth factor gene to treat severe peripheral arterial disease. Arterioscler Thromb Vasc Biol. 2012; 32:2503-9.

10. Ajroud-Driss S, Christiansen M, Allen JA, Kessler JA. Phase 1/2 open-label dose-escalation study of plasmid DNA expressing two isoforms of hepatocyte growth factor in patients with painful diabetic peripheral neuropathy. Mol Ther. 2013; 21:1279-86.

11. Gu YQ, Zhang J, Guo LR, Cui S, Li X, Ding D, Kim Jk, Ho SH, Hahn W, Kim S, A phase I clinical study of naked DNA expressing two isoforms of hepatocyte growth factor to treat patients with critical limb ischemia. J Gene Med 2011; 13: 602-610.

12. Henry TD, Hirsh AT, Goldman J, Wang YL, Lips DL, McMillan WD, Duval S, Bigg TA, Keo HH, Safety of a non-viral plasmid-encoding dual isoforms of hepatocyte growth factor in critical limb ischemia patients: a phase I study. Gene Ther $2011 ; 18: 788-794$.

13. Ha XQ, Li YM, Bi JJ, Zhang QL, Wu ZZ. Plasmid pUDKH gene therapy of rat acute hind limb ischemia: an experimental study. Natl Med J China. 2003; 83: 1521-1524.

14. Ha XQ, Yuan B, Li YM, Yao SL, Wu ZZ. Application of gene gun in treatment of occlusive vascular diseases in rats. Let Biotech. 2001; 12:266-269.

15. Ha XQ, Ren JP, Bi JJ, Zhang JH, Zhang QL, Wu ZZ. Human hepatocyte growth factor for gene therapy of peripheral arterial occlusive disease in dogs. Chin Sci Bull. 2003; 48:571-574

16. Yang YF, Wang RL, Liu YX, Wang H, Bi JJ, Zhang QL, Wu ZZ, LS Wang. Distribution of recombinant plasmid carrying hepatocyte growth factor gene in rat. Chin Med Biotech. 2008; 3: 273-278.

17. Bi JJ, Wu DL, Zhang JH, Jin JD, Wang YF, Gong P, Wang XN, Zhang QL, Wu ZZ. Safety evaluation on the treatment of periphery artery disease by plasmid. Let Biotech. 2002; 13: 443-444.

18. Hu C, Lu Y, Chen X, Wu Z, Zhang Q. Gene transfer of a naked plasmid (pUDK- HGF) encoding human hepatocyte growth factor attenuates skin/muscle incision and retraction-induced chronic post-surgical pain in rats. J Gene Med. $2017 ; 19(12)$

19. Hu C, Lu Y, Cheng X, Cui Y, Wu Z, Zhang Q. Gene therapy for neuropathic pain induced by spared nerve injury with naked plasmid encoding hepatocyte growth factor. Eur J Pain. 2018: 22(5): 961-972.

20. Hauser CJ., Shoemaker W C., Use of a Transcutaneous $\mathrm{PO}_{2}$ regional perfusion index to quantify tissue perfusion in peripheral vascular disease, Ann. Surg, 1983;197(3): 337-343

\section{Tables}

\section{Table 1. Rest pain patient characteristics at baseline}




\begin{tabular}{|c|c|c|c|c|c|c|}
\hline item & & placebo & low-dose & mid-dose & high-dose & p-value \\
\hline $\mathrm{N}$ & & 34 & 27 & 30 & 28 & \\
\hline Age & $\operatorname{Mean}(\mathrm{Sd})$ & $55.00(13.04)$ & $58.67(14.52)$ & $56.67(17.03)$ & $56.32(15.98)$ & 0.7346 \\
\hline Gender & male, $\mathrm{n}(\%)$ & $29(85.29)$ & 24(88.89) & $26(86.67)$ & 23(82.14) & 0.9108 \\
\hline \multicolumn{7}{|c|}{ Systolic pressure } \\
\hline & Mean(Sd) & $130.59(15.74)$ & 131.33(11.77) & $134.40(18.81)$ & 131.96(19.89) & 0.9216 \\
\hline \multicolumn{7}{|c|}{ Diastolic pressure } \\
\hline & Mean(Sd) & $81.65(9.37)$ & $79.15(6.94)$ & 78.93(11.00) & 76.46(13.18) & 0.2100 \\
\hline \multicolumn{7}{|c|}{ Classification of limb ischemic diseases } \\
\hline & ASO (\%) & 19(55.88) & $17(62.96)$ & $17(56.67)$ & $18(64.29)$ & 0.8439 \\
\hline & TAO (\%) & $15(44.12)$ & $9(33.33)$ & $11(36.67)$ & \multicolumn{2}{|l|}{$9(32.14)$} \\
\hline & Others (\%) & $0(0.00)$ & $1(3.70)$ & $2(6.67)$ & $1(3.57)$ & \\
\hline \multicolumn{7}{|c|}{ History of peripheral vascular surgery or interventional therapy } \\
\hline \multicolumn{2}{|c|}{ Yes (\%) } & $17(50.00)$ & 14(51.85) & $12(40.00)$ & $12(42.86)$ & 0.7711 \\
\hline \multicolumn{7}{|c|}{ Medicine therapy history of limb ischemic diseases within one month } \\
\hline \multicolumn{2}{|c|}{ Yes (\%) } & $25(73.53)$ & 19(70.37) & $18(60.00)$ & 18(64.29) & 0.6726 \\
\hline
\end{tabular}

Table 2. Ulcer patient characteristics at baseline 


\begin{tabular}{|c|c|c|c|c|c|c|c|}
\hline & & placebo & low-dose & \multicolumn{2}{|c|}{ mid-dose } & high-dose & $p$ value \\
\hline \multicolumn{2}{|l|}{$\mathrm{N}$} & 30 & 31 & \multicolumn{2}{|l|}{30} & 30 & \\
\hline Age & Mean(Sd) & $53.63(13.28)$ & $59.48(14.44)$ & \multicolumn{2}{|c|}{$51.27(11.58)$} & $49.50(12.65)$ & 0.0133 \\
\hline Gender & $\begin{array}{l}\text { male, } \\
\mathrm{n}(\%)\end{array}$ & $29(96.67)$ & $24(77.42)$ & \multicolumn{2}{|c|}{$26(86.67)$} & $27(90.00)$ & 0.1468 \\
\hline \multicolumn{8}{|c|}{ Systolic pressure } \\
\hline & Mean(Sd) & $134.70(18.14)$ & $133.35(17.55)$ & \multicolumn{2}{|c|}{$133.40(14.10)$} & $128.40(13.10)$ & 0.4189 \\
\hline \multicolumn{8}{|c|}{ Diastolic pressure } \\
\hline & Mean(Sd) & $78.50(9.03)$ & $78.74(9.22)$ & \multicolumn{2}{|c|}{$81.10(10.50)$} & $78.53(7.75)$ & 0.6040 \\
\hline \multicolumn{8}{|c|}{ Classification of limb ischemic diseases } \\
\hline \multicolumn{2}{|c|}{ ASO (\%) } & $17(56.67)$ & $20(64.52)$ & $12(40.00)$ & $7(23.33)$ & \multicolumn{2}{|l|}{0.0141} \\
\hline \multicolumn{2}{|c|}{ TAO (\%) } & $13(43.33)$ & $10(32.26)$ & $17(56.67)$ & \multicolumn{2}{|c|}{$21(70.00)$} & \\
\hline \multicolumn{2}{|c|}{$\begin{array}{l}\text { others } \\
(\%)\end{array}$} & $.00)$ & $1(3.23)$ & 1(3.33) & \multicolumn{2}{|l|}{$2(6.67)$} & \\
\hline \multicolumn{8}{|c|}{ History of peripheral vascular disease surgery or interventional therapy } \\
\hline \multicolumn{2}{|c|}{ Yes (\%) } & $4(13.33)$ & $14(45.16)$ & 13(43.33) & $9(30.00)$ & \multicolumn{2}{|l|}{0.0319} \\
\hline \multicolumn{8}{|c|}{ Medicne therapy history of limb ischemic diseases within one month } \\
\hline \multicolumn{2}{|c|}{ Yes (\%) } & 70.00) & $25(80.65)$ & $21(70.00)$ & $21(70.00)$ & 0.7276 & \\
\hline
\end{tabular}

Table 3. VAS score changes in rest pain patients available for efficacy 


\begin{tabular}{|c|c|c|c|c|}
\hline Follow-up & Placebo & Low-dose & Medial-dose & High-dose \\
\hline $\mathrm{N}(100)$ & 29 & 24 & 25 & 22 \\
\hline \multicolumn{5}{|l|}{ Screening } \\
\hline $\operatorname{Mean}(\mathrm{Sd})$ & $5.84(1.25)$ & $5.90(1.26)$ & $5.84(1.29)$ & $6.00(1.22)$ \\
\hline Median & 5.5 & 6.0 & 6.0 & 6.0 \\
\hline $\operatorname{Min} \rrbracket \operatorname{Max}$ & $4.0 \sim 8.5$ & $4.0 \sim 8.5$ & $4.0 \sim 8.5$ & $4.0 \sim 8.5$ \\
\hline $\mathrm{p}$ & 0.9696 & & & \\
\hline \multicolumn{5}{|l|}{ Day 0} \\
\hline Mean(Sd) & $5.76(1.24)$ & $5.90(1.28)$ & $5.90(1.30)$ & $5.89(1.27)$ \\
\hline Median & 5.0 & 6.0 & 6.0 & 6.0 \\
\hline $\operatorname{Min} \llbracket \operatorname{Max}$ & $4.0 \sim 8.5$ & $4.0 \sim 8.5$ & $4.0 \sim 8.5$ & $3.0 \sim 8.5$ \\
\hline$p$ & 0.9714 & & & \\
\hline \multicolumn{5}{|l|}{ Day 14} \\
\hline Mean(Sd) & $5.00(1.50)$ & $4.94(1.38)$ & $4.72(1.56)$ & $4.55(1.51)$ \\
\hline Median & 5.0 & 4.7 & 4.0 & 4.5 \\
\hline $\operatorname{Min} \llbracket \operatorname{Max}$ & $2.0 \sim 8.0$ & $3.0 \sim 8.5$ & $3.0 \sim 8.0$ & $0.0 \sim 7.5$ \\
\hline $\mathrm{p}$ & 0.6983 & & & \\
\hline \multicolumn{5}{|l|}{ Day 28} \\
\hline Mean(Sd) & $4.44(1.55)$ & $3.82(1.51)$ & $3.40(1.79)$ & $3.82(1.23)$ \\
\hline Median & 4.0 & 3.5 & 3.0 & 4.0 \\
\hline $\operatorname{Min} \rrbracket \operatorname{Max}$ & $2.0 \sim 7.5$ & $2.0 \sim 7.0$ & $0.0 \sim 7.5$ & $2.0 \sim 7.0$ \\
\hline $\mathrm{p}$ & 0.1053 & & & \\
\hline \multicolumn{5}{|l|}{ Day 60} \\
\hline Mean(Sd) & $3.62(1.46)$ & $2.49(1.63)$ & $2.72(1.65)$ & $3.16(1.10)$ \\
\hline Median & 3.5 & 2.0 & 3.0 & 3.0 \\
\hline $\operatorname{Min} \llbracket \operatorname{Max}$ & $0.0 \sim 6.0$ & $0.0 \sim 6.0$ & $0.0 \sim 6.0$ & $1.5 \sim 6.0$ \\
\hline $\mathrm{p}$ & 0.0338 & & & \\
\hline \multicolumn{5}{|l|}{ Day 90} \\
\hline Mean(Sd) & $2.95(1.62)$ & $1.80(1.58)$ & $1.89(1.49)$ & $1.95(1.70)$ \\
\hline Median & 3.0 & 1.0 & 2.0 & 2.0 \\
\hline $\operatorname{Min} \llbracket \operatorname{Max}$ & $0.0 \sim 7.0$ & $0.0 \sim 5.5$ & $0.0 \sim 4.0$ & $0.0 \sim 7.0$ \\
\hline $\mathrm{p}$ & 0.0301 & & & \\
\hline Day 180 & & & & \\
\hline
\end{tabular}




\begin{tabular}{|lllll|}
\hline Follow-up & Placebo & Low-dose & Medial-dose & High-dose \\
\hline Mean(Sd) & $1.86(1.69)$ & $0.94(1.37)$ & $0.46(0.88)$ & $1.00(1.66)$ \\
\hline Median & 2.0 & 0.0 & 0.0 & 0.0 \\
Min囚Max & $0.0 \sim 6.0$ & $0.0 \sim 4.0$ & $0.0 \sim 3.0$ & $0.0 \sim 6.0$ \\
$\mathrm{p}$ & 0.0055 & & & \\
\hline
\end{tabular}

Table 4. The ulcer size changes and healing of ulcer patients on day 180 


\begin{tabular}{|c|c|c|c|c|c|}
\hline & Placebo & Low-dose & Medial-dose & High-dose & $p$ \\
\hline \multicolumn{6}{|c|}{ Baseline ulcer area $<1000 \mathrm{~mm}^{2}$} \\
\hline $\mathrm{N}$ & 18 & 18 & 24 & 18 & \\
\hline \multicolumn{6}{|l|}{ Day 0} \\
\hline $\begin{array}{l}\text { Ulcer area, } \\
\text { Mean (Sd) }\end{array}$ & $323.79(247.75)$ & $250.17(251.61)$ & $256.26(245.83)$ & 266.15(200.33) & 0.7745 \\
\hline Median & 256.61 & 124.13 & 216.48 & 234.36 & \\
\hline $\operatorname{Min} \varangle \operatorname{Max}$ & $59.58 \sim 935.28$ & $14.53 \sim 963.00$ & $12.79 \sim 957.61$ & $31.00 \sim 675.71$ & \\
\hline \multicolumn{6}{|l|}{ Day 180} \\
\hline $\begin{array}{l}\text { Ulcer area, } \\
\text { Mean (Sd) }\end{array}$ & $317.09(836.90)$ & 138.38(337.32) & $51.95(118.96)$ & $91.30(170.86)$ & 0.2790 \\
\hline Median & 46.88 & 0 & 0 & 0 & \\
\hline $\operatorname{Min} \rrbracket \operatorname{Max}$ & $0.00 \sim 3469.59$ & $0.00 \sim 1381.77$ & $0.00 \sim 409.74$ & $0.00 \sim 541.02$ & \\
\hline $\begin{array}{l}\text { Complete } \\
\text { closure, n (\%) }\end{array}$ & 8/18(44.4) & 11/18(61.1) & 18/24(75.0) & 10/18(55.6) & 0.3190 \\
\hline $\begin{array}{l}\geq 50 \% \\
\text { reduction, n } \\
(\%)\end{array}$ & 13/18(72.22) & 13/18(72.22) & 20/24(83.33) & 14/18(77.78) & 0.7792 \\
\hline \multicolumn{6}{|c|}{ Baseline ulcer area $\geq 1000 \mathrm{~mm}^{2}$} \\
\hline $\mathrm{N}$ & 5 & 1 & 1 & 4 & \\
\hline \multicolumn{6}{|l|}{ Day 0} \\
\hline $\begin{array}{l}\text { Ulcer area, } \\
\text { Mean (Sd) }\end{array}$ & 2319.76(1564.54) & 1124.00 & 1027.65 & 1829.05(312.40) & \\
\hline Median & 1466.48 & 1124.00 & 1027.65 & 1826.50 & \\
\hline Min『Max & $1319.19 \sim 5000.49$ & 1124.00 & 1027.65 & $1486.80 \sim 2176.39$ & \\
\hline \multicolumn{6}{|l|}{ Day 180} \\
\hline $\begin{array}{l}\text { Ulcer area, } \\
\text { Mean (Sd) }\end{array}$ & $381.67(411.62)$ & 1680.00 & 3089.22 & $458.25(462.71)$ & \\
\hline Median & 182.75 & 1680.00 & 3089.22 & 385.95 & \\
\hline $\operatorname{Min} \rrbracket \operatorname{Max}$ & $162.50 \sim 998.68$ & 1680.00 & 3089.22 & $0.00 \sim 1061.11$ & \\
\hline $\begin{array}{l}\text { Complete } \\
\text { closure, n(\%) }\end{array}$ & $0 / 5(0.0)$ & $0 / 1(0.0)$ & $0 / 1(0.0)$ & $1 / 4(25.0)$ & \\
\hline $\begin{array}{l}\geq 50 \% \\
\text { reduction, } n(\%)\end{array}$ & $4 / 5(80.0)$ & $0 / 1(0.0)$ & $0 / 1(0.0)$ & $4 / 4(100.0)$ & \\
\hline
\end{tabular}

\section{Figures}




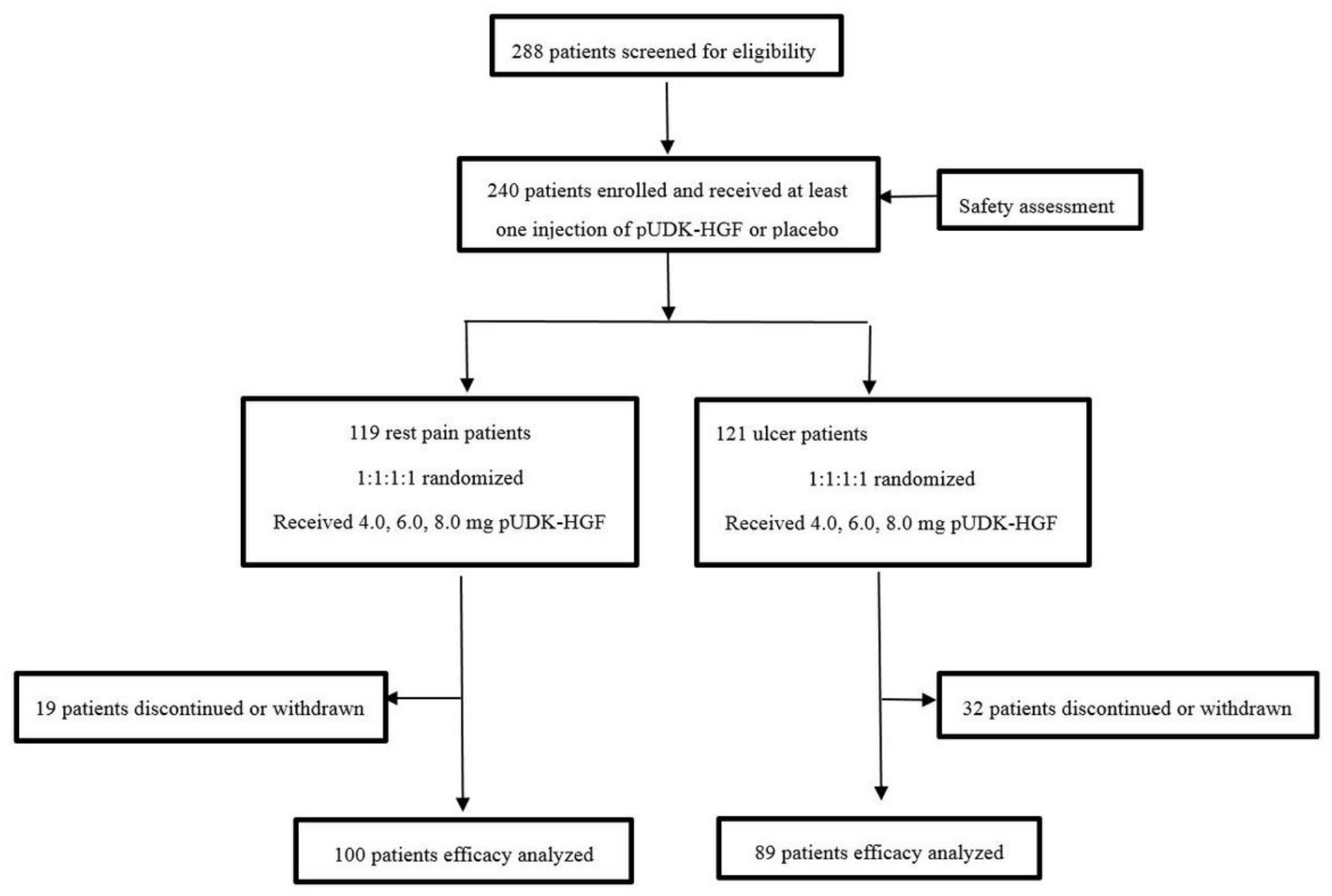

Figure 1

pUDK-HGF phase II clinical trial flow chart. Two cohorts of patients (119 pain at rest patients and 121 ulcer patients ) were enrolled and randomized 1:1:1:1 to receive intramuscular injection of placebo ( $0.9 \%$ saline), or 1 of 3 doses of pUDK-HGF (low-dose, 4.0; middle-dose, 6.0; high-dose, $8.0 \mathrm{mg}$ ) on days 0, 14, and 28. In the pain-at-rest cohort, 19 patients discontinued or were withdrawn and 100 patients were available for the efficacy analysis. In the ulcer patient cohort, eighty-nine patients completed the study and were available for the efficacy analysis. 240 patients in two cohorts received at least one injection of pUDK-HGF or placebo were available for safety assessment. 


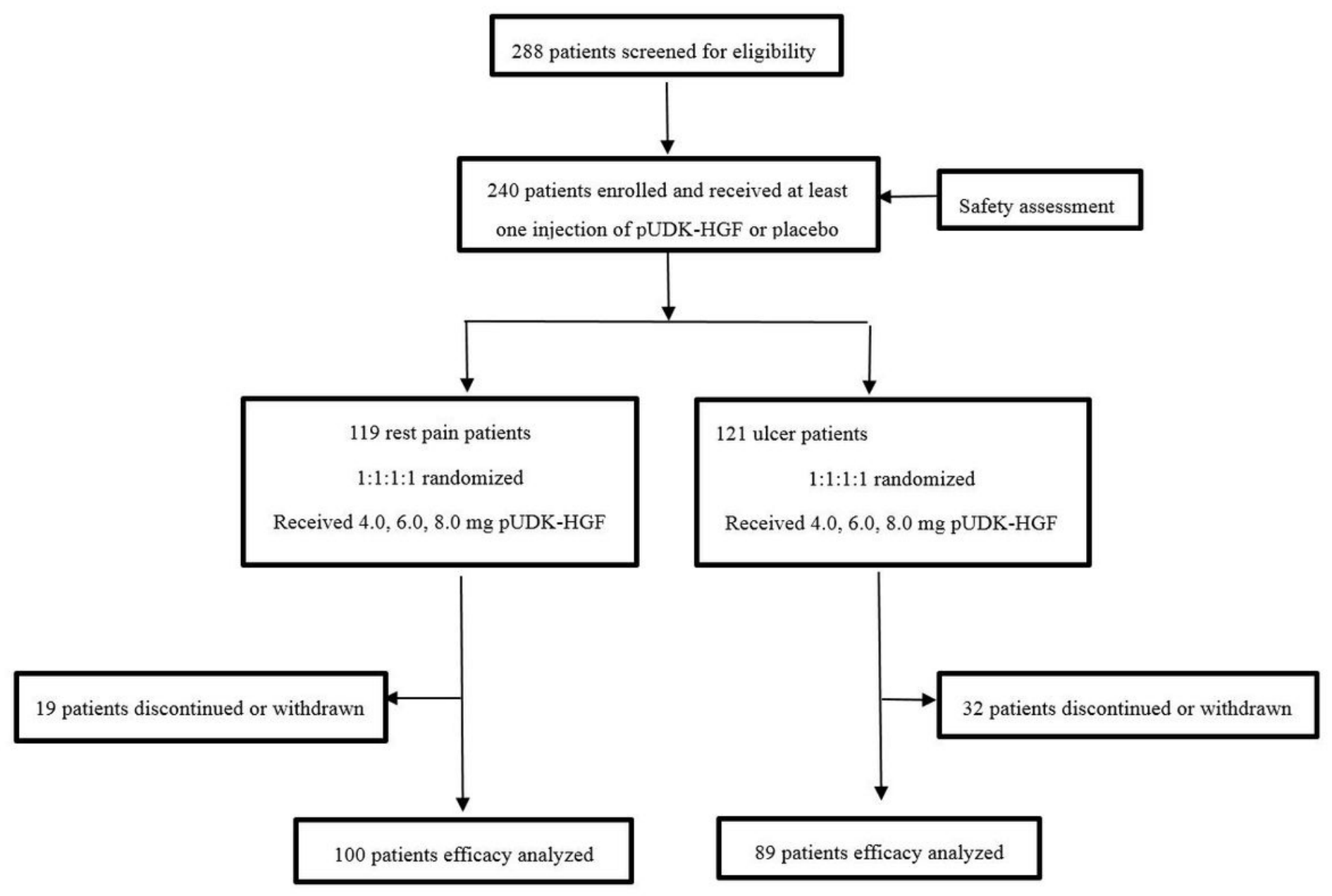

Figure 1

pUDK-HGF phase II clinical trial flow chart. Two cohorts of patients (119 pain at rest patients and 121 ulcer patients ) were enrolled and randomized 1:1:1:1 to receive intramuscular injection of placebo ( $0.9 \%$ saline), or 1 of 3 doses of pUDK-HGF (low-dose, 4.0; middle-dose, 6.0; high-dose, $8.0 \mathrm{mg}$ ) on days 0, 14, and 28. In the pain-at-rest cohort, 19 patients discontinued or were withdrawn and 100 patients were available for the efficacy analysis. In the ulcer patient cohort, eighty-nine patients completed the study and were available for the efficacy analysis. 240 patients in two cohorts received at least one injection of pUDK-HGF or placebo were available for safety assessment. 


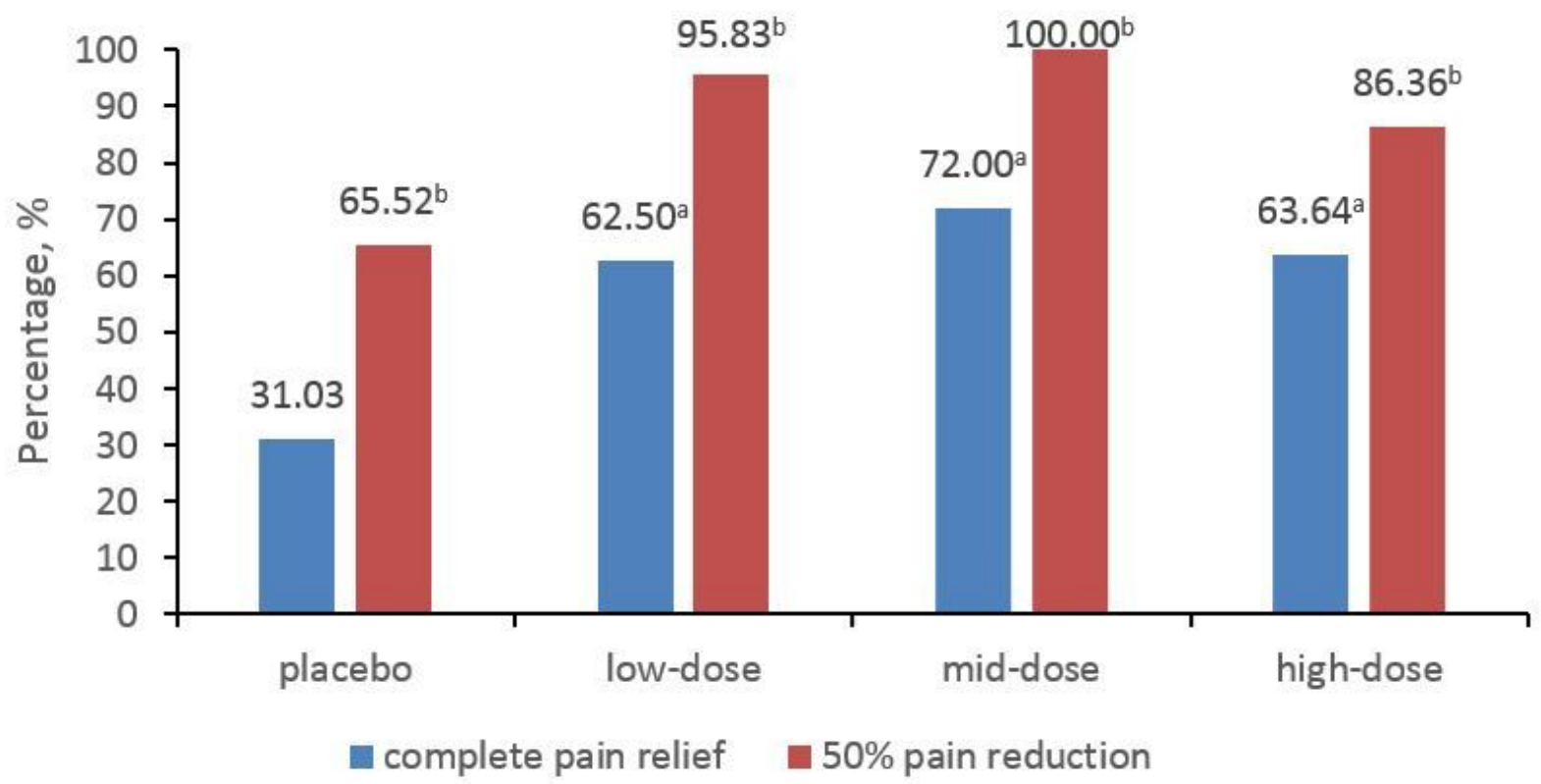

\section{Figure 2}

The percentages of complete pain relief and $>50 \%$ pain reduction in rest pain patient cohort on day 180 . A significantly higher proportion of patients in the pUDK-HGF groups $(62.50 \%, 72.00 \%$, or $63.64 \%$ in the high-dose, mid-dose, or lowdose group, respectively) achieved complete pain relief primary end point on day 180 , compared with patients in the placebo group (31.03\%, $p=0.0148$ ). The number of responding patients with $>50 \%$ pain relief in all the pUDK-HGF groups was also significantly higher than the number in the placebo group $(65.52 \%$ for the placebo versus $86.36 \%$, $100.00 \%$, or $95.83 \%$ for the high-dose, mid-dose, or low-dose groups, respectively; $p=0.0168)$. $a, b, p<0.05$ by Fisher's exact test, placebo versus low-, middle-, or high-dose pUDK-HGF, respectively. 


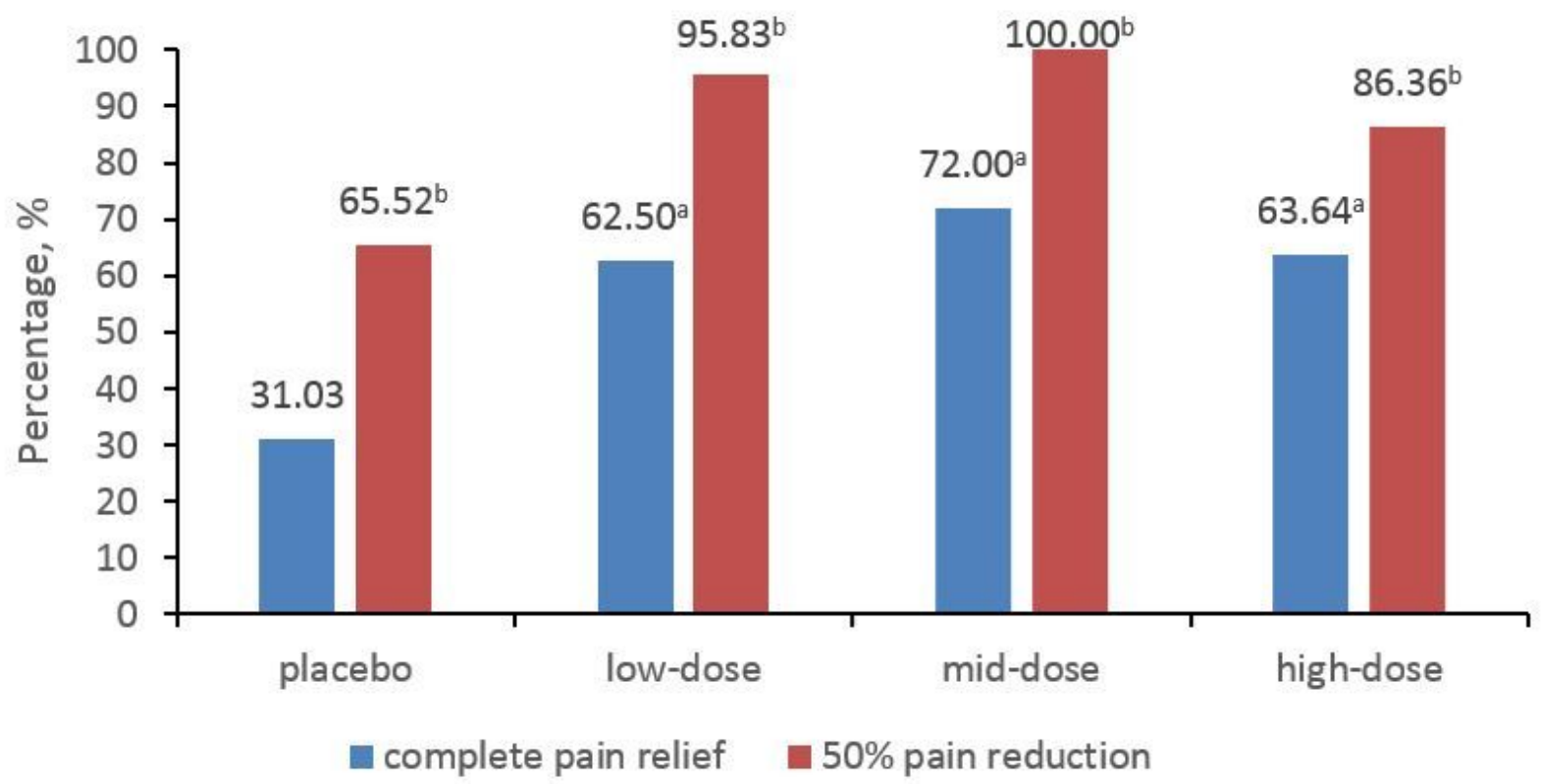

\section{Figure 2}

The percentages of complete pain relief and $>50 \%$ pain reduction in rest pain patient cohort on day 180 . A significantly higher proportion of patients in the pUDK-HGF groups $(62.50 \%, 72.00 \%$, or $63.64 \%$ in the high-dose, mid-dose, or lowdose group, respectively) achieved complete pain relief primary end point on day 180 , compared with patients in the placebo group (31.03\%, $p=0.0148$ ). The number of responding patients with $>50 \%$ pain relief in all the pUDK-HGF groups was also significantly higher than the number in the placebo group $(65.52 \%$ for the placebo versus $86.36 \%$, $100.00 \%$, or $95.83 \%$ for the high-dose, mid-dose, or low-dose groups, respectively; $p=0.0168)$. $a, b, p<0.05$ by Fisher's exact test, placebo versus low-, middle-, or high-dose pUDK-HGF, respectively. 


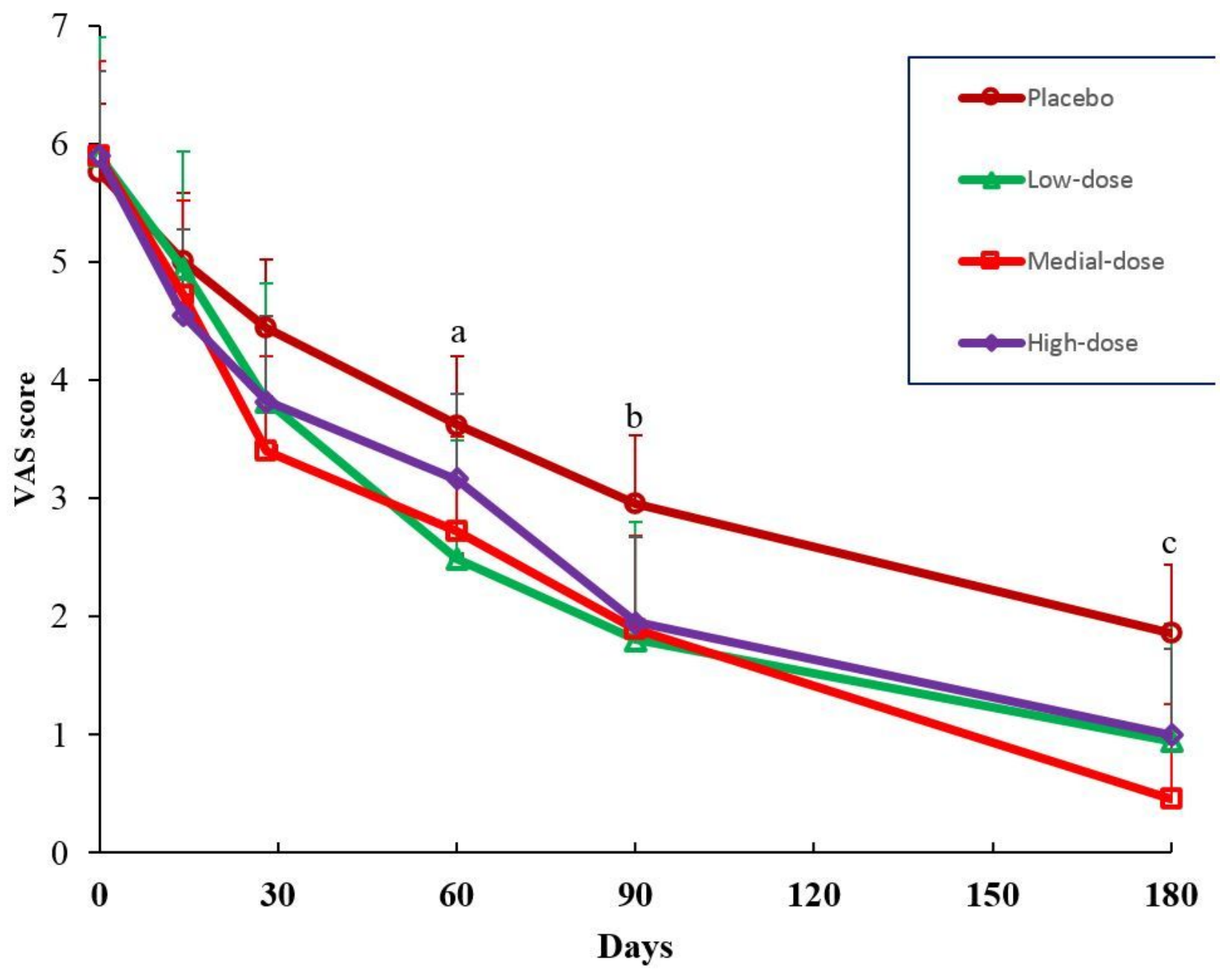

Figure 3

The VAS score change from baseline over the 6-month follow-up in rest pain patient cohort. After the first injection of pUDK-HGF on day 0 , the VAS score reduced and showed statistically significant differences on days 60,90 and 180 among the placebo and pUDK-HGF groups. pUDK-HGF treatment experienced long-term pain relief. $a, b, c, p<0.05$, placebo versus low-, middle-, or high-dose pUDK-HGF, respectively. 


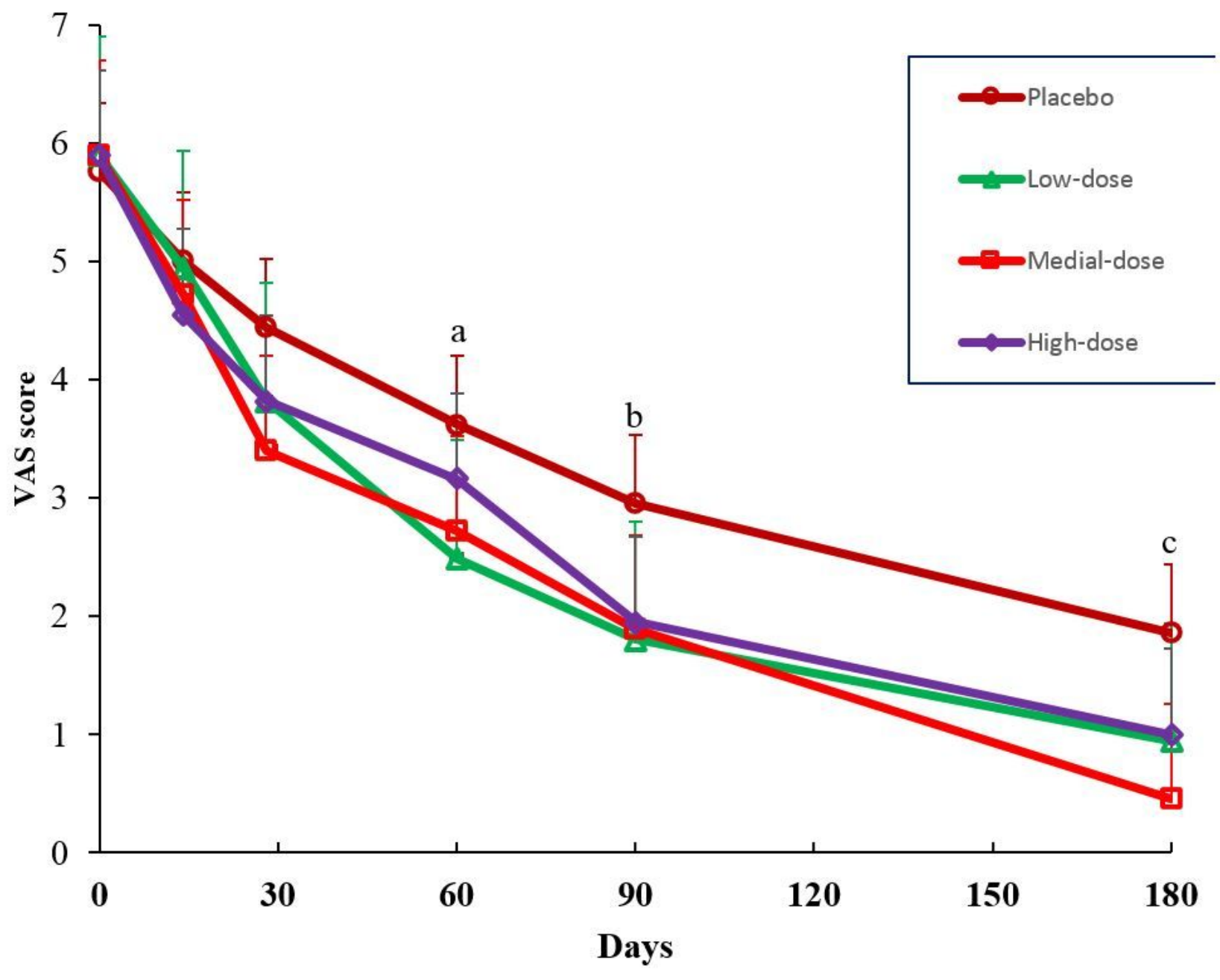

Figure 3

The VAS score change from baseline over the 6-month follow-up in rest pain patient cohort. After the first injection of pUDK-HGF on day 0 , the VAS score reduced and showed statistically significant differences on days 60,90 and 180 among the placebo and pUDK-HGF groups. pUDK-HGF treatment experienced long-term pain relief. $a, b, c, p<0.05$, placebo versus low-, middle-, or high-dose pUDK-HGF, respectively. 


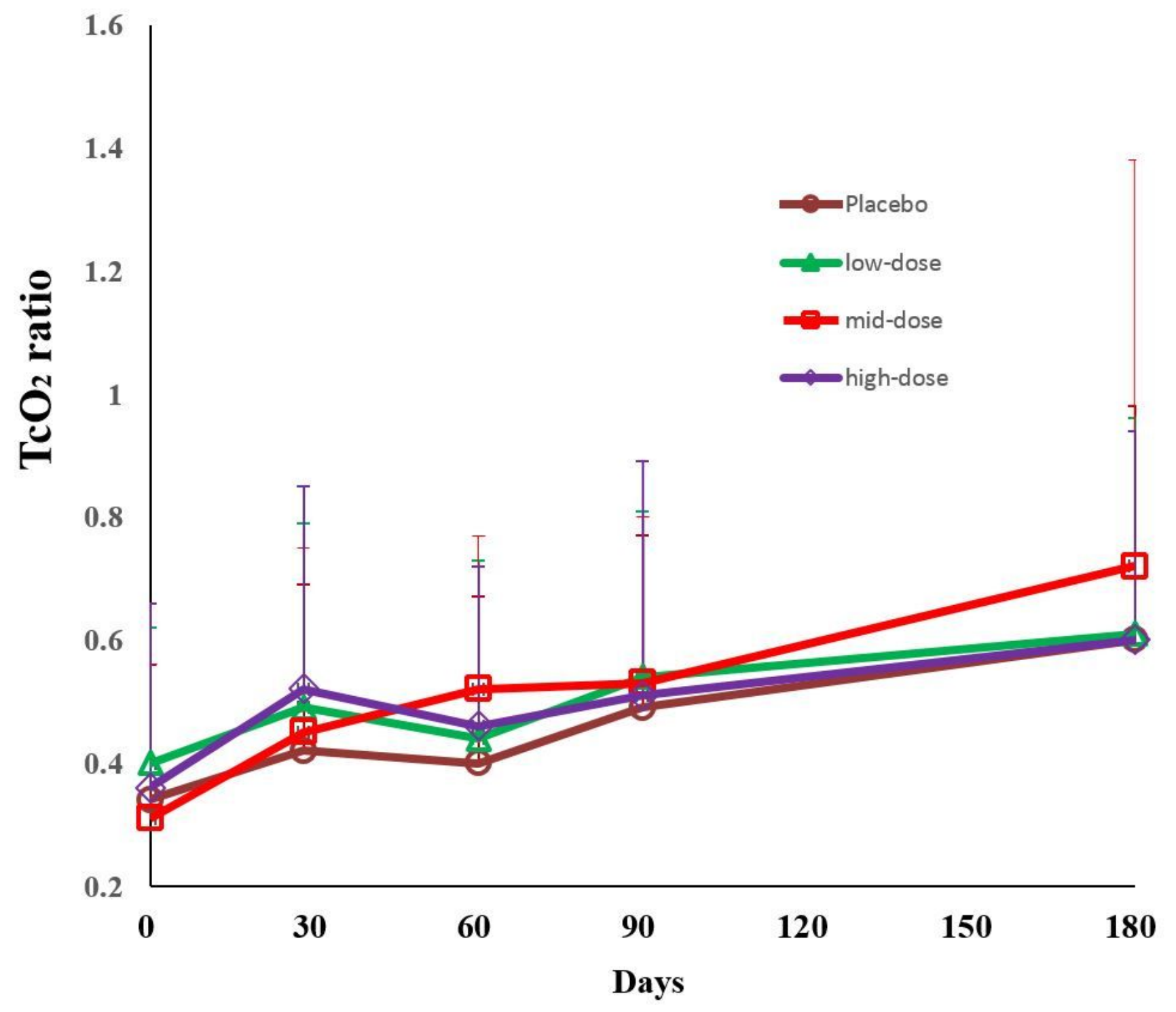

Figure 4

The changes of TCPO2 ratio from baseline over the 6-month follow-up in rest pain patient cohort. The TcPO2 ratio in each group significantly increased from baseline onwards but no statistically difference by Fisher's exact test among groups at any visiting time points. 


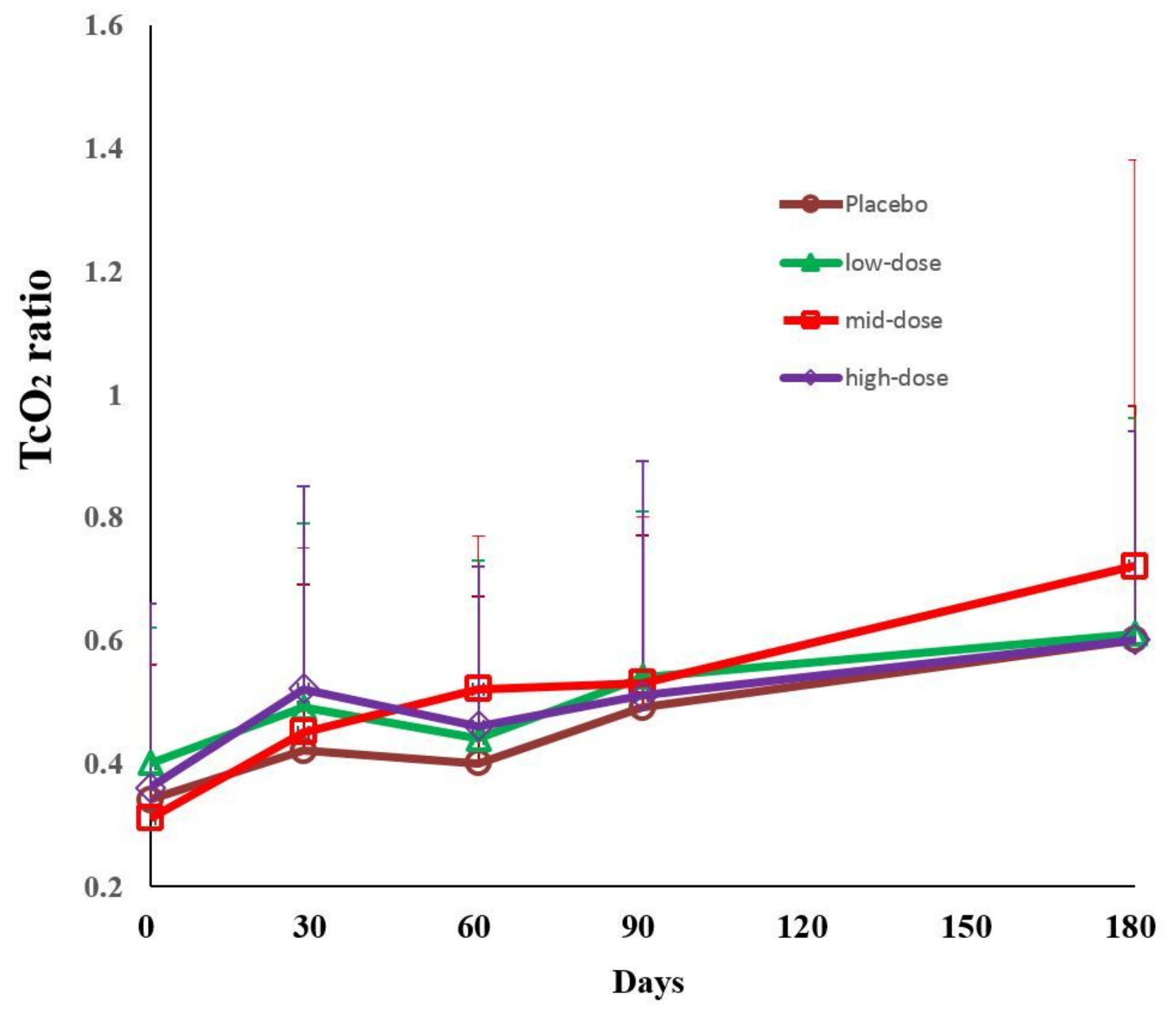

Figure 4

The changes of TCPO2 ratio from baseline over the 6-month follow-up in rest pain patient cohort. The TcPO2 ratio in each group significantly increased from baseline onwards but no statistically difference by Fisher's exact test among groups at any visiting time points. 


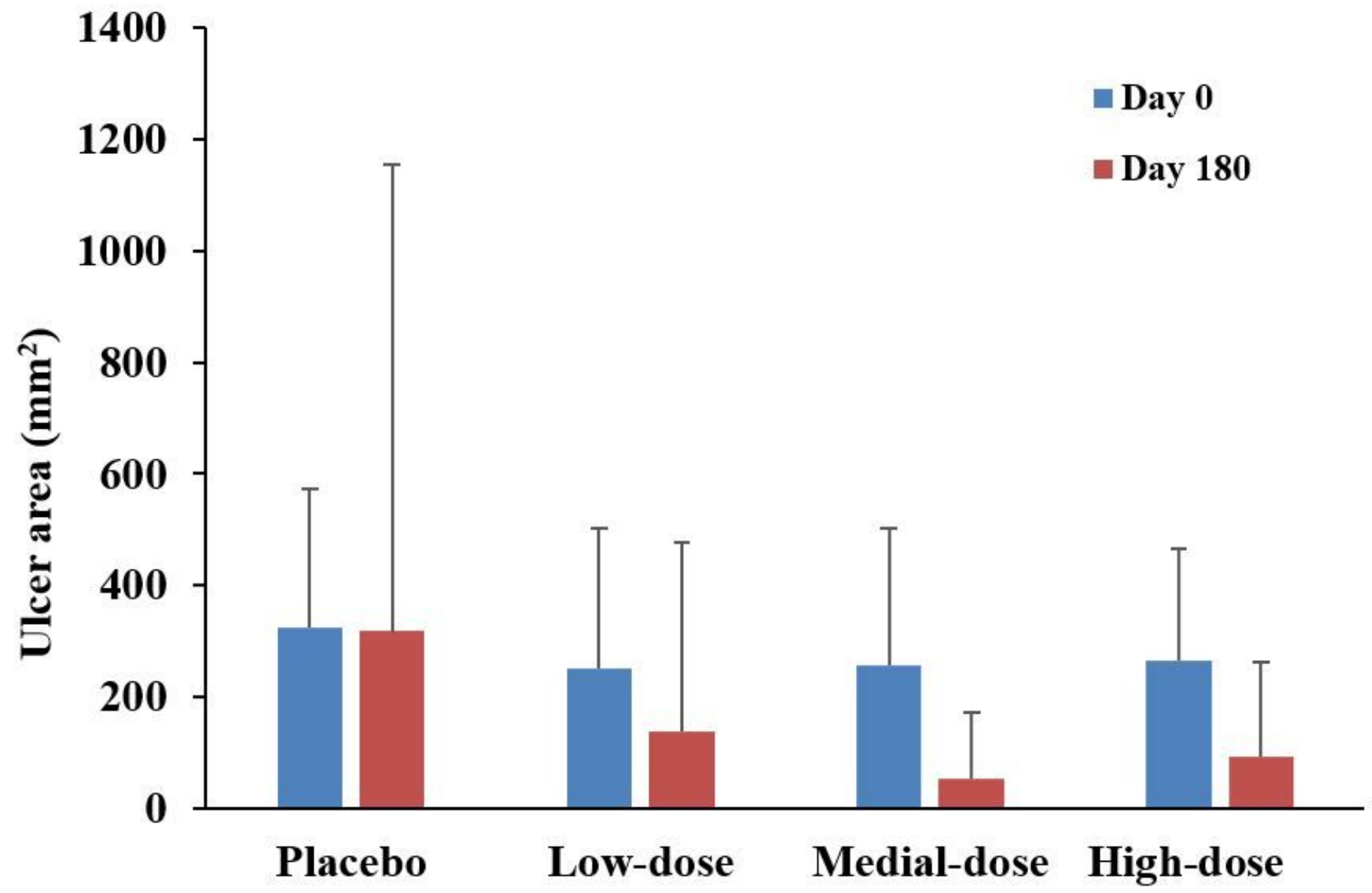

Figure 5

The ulcer area changes from baseline to 6 months in patients with ulcer $<1000 \mathrm{~mm} 2$ at baseline. pUDK-HGF treatment tended to be superior to the placebo in promoting ulcer healing. No statistically difference among groups on day 180 . 


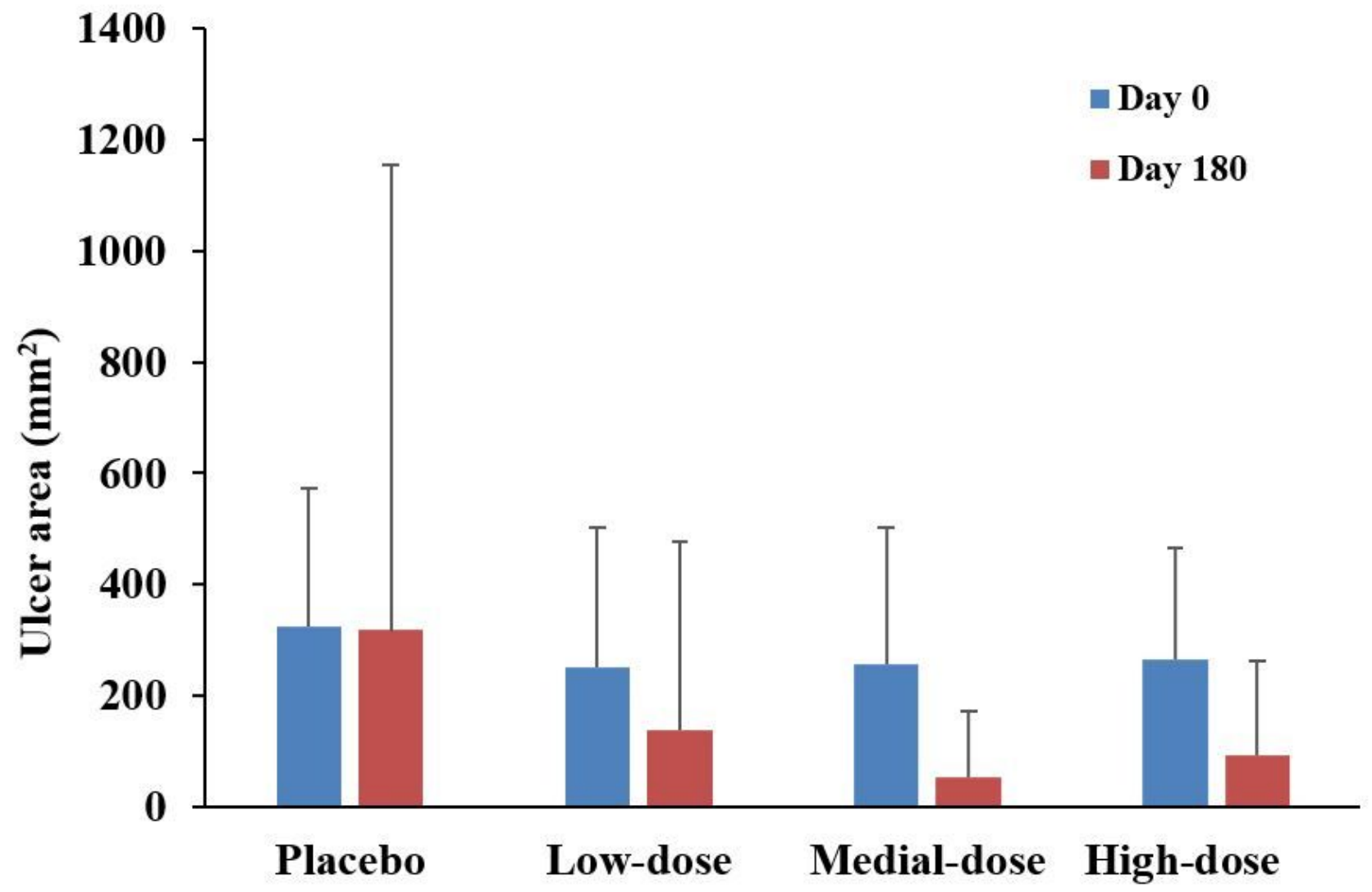

Figure 5

The ulcer area changes from baseline to 6 months in patients with ulcer $<1000 \mathrm{~mm} 2$ at baseline. pUDK-HGF treatment tended to be superior to the placebo in promoting ulcer healing. No statistically difference among groups on day 180 .

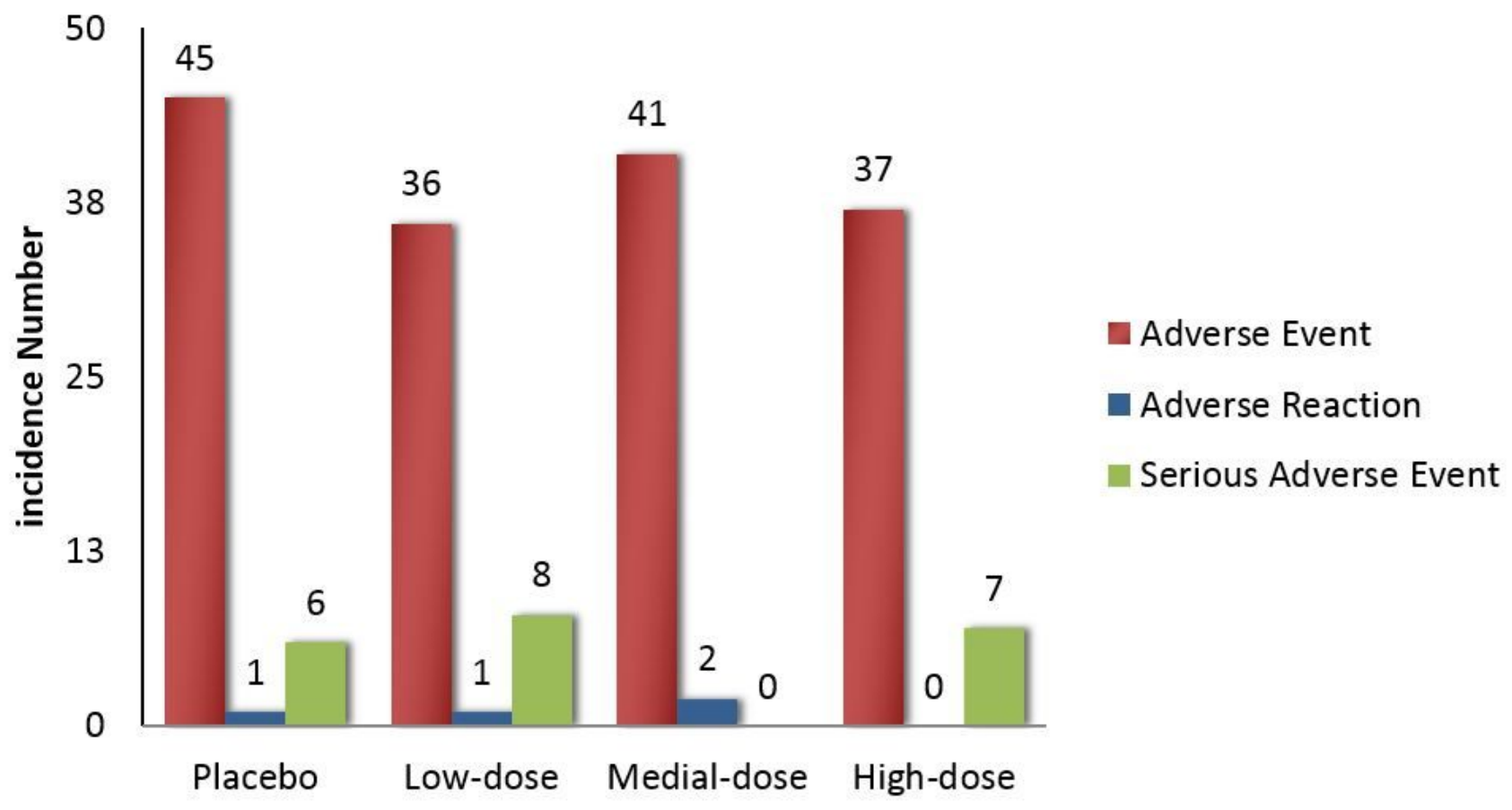


Figure 6

The incidence of Adverse Events, Serious Adverse Events, Adverse Reaction in placebo and low-, middle-, or high-dose pUDK-HGF groups. Intramuscular injections of pUDK-HGF were well tolerated. There were no statistically significant differences in the occurrence of adverse events (AEs), SAEs, adverse reactions or injection-site reactions among the three pUDK-HGF and placebo groups.

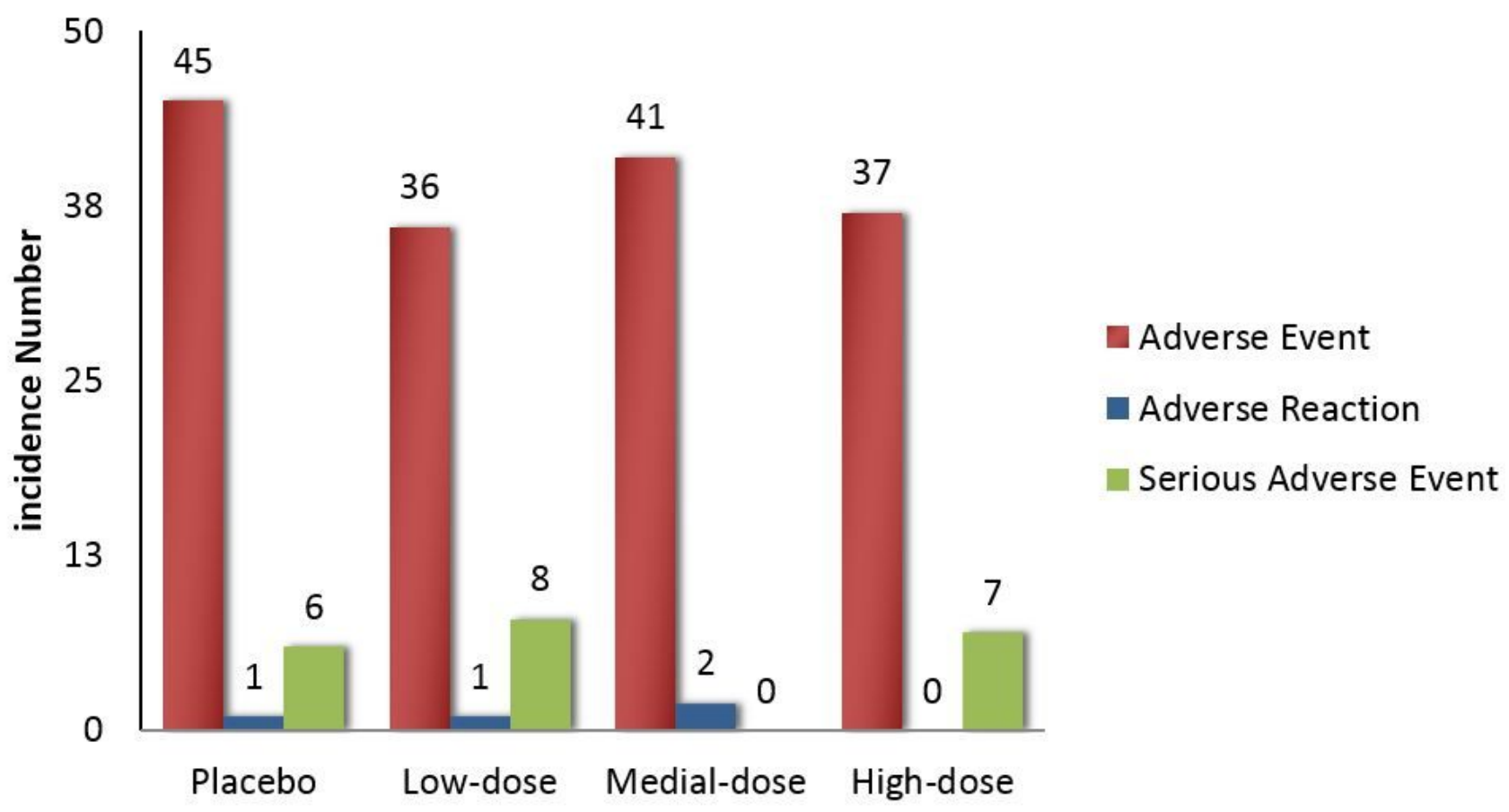

Figure 6

The incidence of Adverse Events, Serious Adverse Events, Adverse Reaction in placebo and low-, middle-, or high-dose pUDK-HGF groups. Intramuscular injections of pUDK-HGF were well tolerated. There were no statistically significant differences in the occurrence of adverse events (AEs), SAEs, adverse reactions or injection-site reactions among the three pUDK-HGF and placebo groups.

\section{Supplementary Files}

This is a list of supplementary files associated with this preprint. Click to download.

- supplementmaterial.docx

- supplementmaterial.docx 